\title{
Three-dimensional terbium(III) metal-organic framework constructed by thiophene-2,5-dicarboxylate: synthesis, crystal structure and fluorescent properties
}

\author{
Xiu-Yue Yu ${ }^{1} \cdot$ Dong-Jie Tian ${ }^{2} \cdot$ Xin Zheng $^{1} \cdot$ Cao-Yuan Niu ${ }^{1}$ (D)
}

Received: 16 May 2020 / Accepted: 7 October 2020 / Published online: 14 October 2020

(c) Springer Nature Switzerland AG 2020

\begin{abstract}
A novel Tb(III) metal-organic framework was synthesized by a multi-layer diffusion method at room temperature. Adjacent $\mathrm{Tb}(\mathrm{III})$ ions were connected together by bridging carboxylic groups to construct one-dimensional chains and the metal-organic framework based on these parallel 1D chains was formed through thiophene-2,5-dicarboxylate bridges. UV-Vis and fluorescent emission spectra as well as theoretical calculation showed that organic ligands acted as sensitizers to $\mathrm{Tb}$ (III) fluorescence. With the excitation of $325 \mathrm{~nm}$, the emission peaks of this compound were found at $488,545,587$, and $621 \mathrm{~nm}$ which were attributed to ${ }^{5} \mathrm{D}_{4} \rightarrow{ }^{7} \mathrm{~F}_{6},{ }^{5} \mathrm{D}_{4} \rightarrow{ }^{7} \mathrm{~F}_{5},{ }^{5} \mathrm{D}_{4} \rightarrow{ }^{7} \mathrm{~F}_{4}$, and ${ }^{5} \mathrm{D}_{4} \rightarrow{ }^{7} \mathrm{~F}_{3}$ transitions, respectively. The quantum yield for solid sample was $36.98 \%$ and this compound can emit strong green light in the solid state.
\end{abstract}

Graphic abstract One new Tb(III) metal-organic framework was synthesized by a multi-layer diffusion method at room temperature using thiophene-2,5-dicarboxylate as the bridging ligand and investigated by single-crystal structure, UVVis absorption, and fluorescent emission.

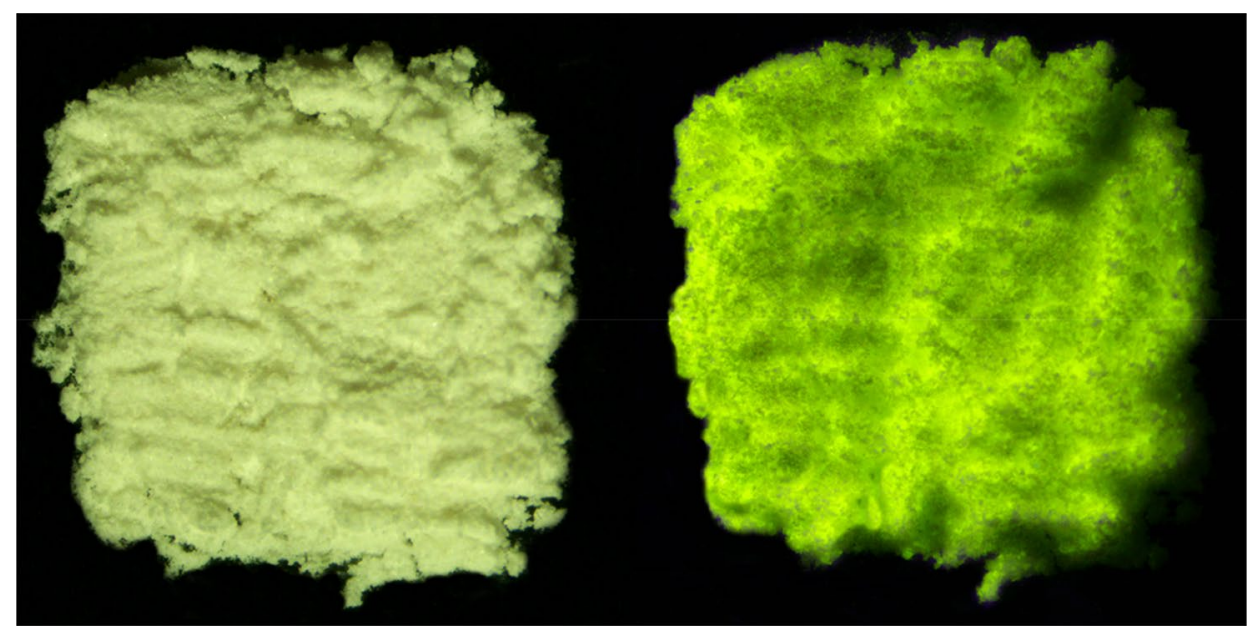

Electronic supplementary material The online version of this article (https://doi.org/10.1007/s42452-020-03642-w) contains supplementary material, which is available to authorized users.

Cao-Yuan Niu, niucaoyuan@henau.edu.cn | ${ }^{1}$ College of Sciences, Henan Agricultural University, Zhengzhou 450002, Henan, P. R. China. ${ }^{2}$ Key Laboratory of Green Chemical Media and Reactions, Collaborative Innovation Center of Henan Province for Green Manufacturing of Fine Chemicals, School of Chemistry and Chemical Engineering, Henan Normal University, Ministry of Education, Xinxiang 453007, Henan, P. R. China. 
Keywords $\mathrm{Tb}(\mathrm{III}) \cdot$ Metal-organic framework $\cdot$ Thiophene-2,5-dicarboxylate $\cdot$ Fluorescence

\section{Introduction}

Metal-organic frameworks (MOFs) have attracted great interests due to the fluorescent properties [1-5], as well as the significant applications, such as magnetism [6-8], gas adsorption and separation [9-11], sensors or detectors [12-17], proton conduction [18], etc. Lanthanide coordination polymers including lanthanide-organic frameworks, one of the important MOFs, are generally synthesized by hydrothermal methods which require high pressure and high temperature that has impeded scalable synthesis of lanthanide MOFs and their industrial utilization [19-21]. Other reported synthetic methods such as solvothermal, microwave-assisted solvothermal, and sonochemical synthesis are also energy consumable [22-24]. Diffusion method, which is seen as low-yield and time-consuming method, has ever been used to synthesize MOFs. However, it is an energy-free method and has seldom been used to synthesize lanthanide MOFs. In our previous work [25], we came up with a three-layer diffusion method with pyridine and some of its basic derivatives acting both as weak bases to deprotonate carboxylic acids (bridging ligands) and as terminal ligands to synthesize coordination polymers with different magnetic properties at room temperature (Scheme 1a). In this work, we applied the same method and successfully synthesized a fluorescent lanthanide metal-organic framework with an angular dicarboxylic acid $\left(\mathrm{H}_{2} \mathrm{~L}\right.$ : thiophene-2,5-dicarboxylic acid) as a bridging ligand under normal pressure at room temperature (Scheme 1b-d).

Among applications of lanthanide MOFs, fluorescence has been widely studied and highlighted because sharp emissive peaks from lanthanide ions are unique and its emission covers a wide range of spectrum from visible to NIR and far NIR. Furthermore, organic ligands as linkers in lanthanide MOFs can act as sensitizers to the emission of lanthanide ions which possess very small molar extinction coefficients $(\varepsilon)$ due to the forbidden nature of $f-f$ transitions in lanthanide atomic shells [22]. However, synthesizing strong emissive lanthanide MOFs with good quantum yield is not easy to be done. In this paper, we synthesized a high yield Tb(III)-MOF showing a strong fluorescent emission and experimentally investigated its fluorescence properties arousing from $\mathrm{Tb}$ (III) ions sensitized by organic ligands in solid state as well as studied with theoretical calculations (Scheme 1d). Its single crystal structure was described and thermal stability by thermogravimetric analysis (TGA) under air atmosphere was also described.

\section{Experimental}

\subsection{Materials and physical measurements}

All reagents and solvents were commercially available without further purification. Flourier transform infrared spectra were recorded on an FTS-40 infrared spectrometer as $\mathrm{KBr}$ pellets. Thermogravimetric analyses were performed under air atmosphere at a heating rate of $10^{\circ} \mathrm{C} /$ min on a Netzsch STA409 PC instrument, in the temperature range of $30-820^{\circ} \mathrm{C}$. UV-Vis spectra were measured by TU-1901 spectrometer. Fluorescent properties were determined by Thermo Scientific Nicolet iS10 spectrometer (for measurement of excitation and emission spectra) and Edinburgh Analytical Instrument FLS980 (for measurement of life time and absolute quantum yield). The morphology of MOFs was investigated by scanning electron microscopy (JSM7001F, NEC).

\subsection{X-ray diffraction studies}

X-ray diffraction data for single crystals were collected on a Bruker SMART APEX-II CCD diffractometer equipped with a graphite crystal and incident beam monochromator using

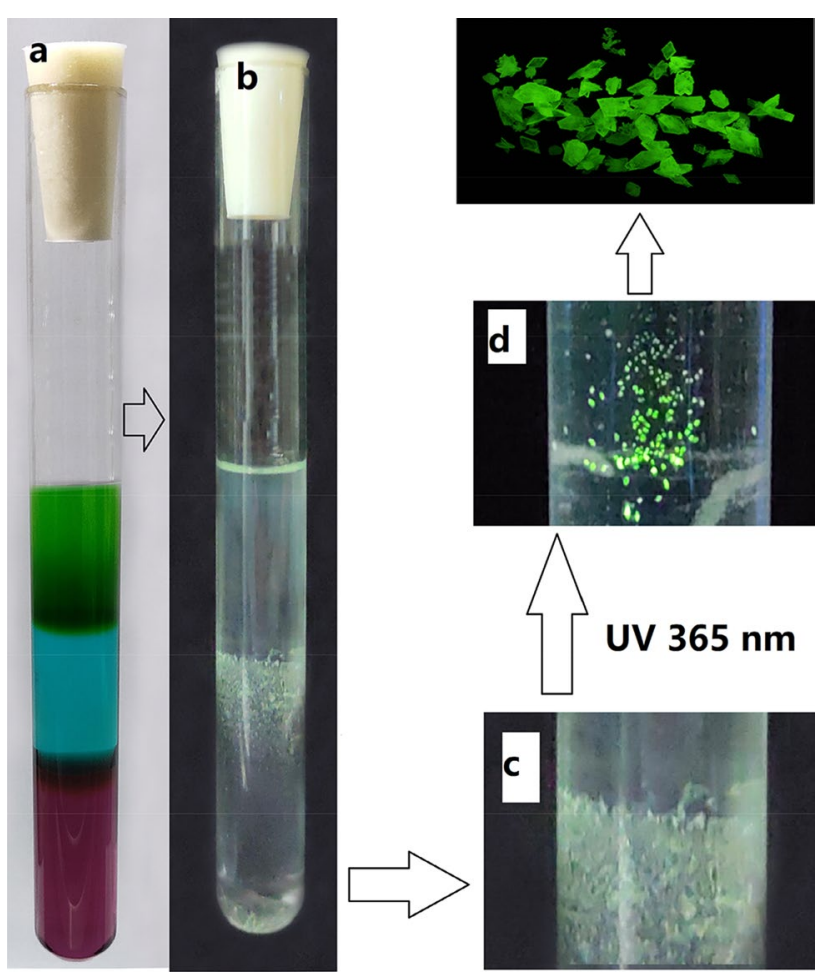

Scheme 1. Synthesis route of fluorescent $\mathrm{Tb}$ (III) MOF 
Table 1 Crystallographic data and structure refinement summary for compound 1

\begin{tabular}{|c|c|}
\hline Compd & 1 \\
\hline Empirical formula & $\mathrm{C}_{30} \mathrm{H}_{24} \mathrm{~N}_{2} \mathrm{O}_{14} \mathrm{~S}_{3} \mathrm{~Tb}_{2}$ \\
\hline Formula weight & 1050.53 \\
\hline Crystal size(mm) & $0.30 \times 0.29 \times 0.26$ \\
\hline Crystal system & triclinic \\
\hline Space group & P-1 \\
\hline$a(\AA)$ & $11.250(4)$ \\
\hline$b(\AA)$ & $12.061(4)$ \\
\hline$c(\AA)$ & $13.480(5)$ \\
\hline$a\left(^{\circ}\right)$ & $93.245(4)$ \\
\hline$\beta\left(^{\circ}\right)$ & $91.197(5)$ \\
\hline$\gamma\left({ }^{\circ}\right)$ & $96.875(4)$ \\
\hline$Z$ & 2 \\
\hline$\rho_{\text {calcd }}\left(\mathrm{g} \cdot \mathrm{cm}^{-3}\right)$ & 1.925 \\
\hline$\mu\left(\mathrm{mm}^{-1}\right)$ & 0.670 \\
\hline$F(000)$ & 1016 \\
\hline $2 \theta$ scan range & $4.42-52.00$ \\
\hline $\mathrm{R}$ (int) & 0.0312 \\
\hline Total reflections & 6914 \\
\hline Unique reflections & 5852 \\
\hline$R 1, w R 2[I>2 \sigma(I)]^{a}$ & $0.0474,0.1347$ \\
\hline Goodness of fit & 1.080 \\
\hline Max/min electron density $\left(\mathrm{e} \AA^{-3}\right.$ ) & $2.315 /-2.333$ \\
\hline
\end{tabular}

${ }^{a} R_{1}=\Sigma|| F_{\mathrm{o}}|-| F_{\mathrm{c}}|| / \Sigma\left|F_{\mathrm{o}}\right| ; w R 2=\left[\Sigma \omega\left(F_{\mathrm{o}}^{2}-F_{\mathrm{c}}{ }^{2}\right)^{2} / \Sigma \omega\left(F_{\mathrm{o}}{ }^{2}\right)^{2}\right]^{1 / 2}$

Table 2 Selected Bond Lengths $(\AA)$ and Angles $\left(^{\circ}\right)$ around Tb atoms for compound 1

\begin{tabular}{llll}
\hline $\mathrm{Tb}(1)-\mathrm{O}(1)$ & $2.446(5)$ & $\mathrm{Tb}(1)-\mathrm{O}(5)$ & $2.470(5)$ \\
$\mathrm{Tb}(1)-\mathrm{O}(2)$ & $2.472(5)$ & $\mathrm{Tb}(1)-\mathrm{O}(12)$ & $2.482(5)$ \\
$\mathrm{Tb}(1)-\mathrm{O}(3)$ & $2.491(4)$ & $\mathrm{Tb}(1)-\mathrm{O}(7)$ & $2.541(5)$ \\
$\mathrm{Tb}(1)-\mathrm{O}(6)$ & $2.609(5)$ & $\mathrm{Tb}(1)-\mathrm{N}(1)$ & $2.733(6)$ \\
$\mathrm{Tb}(2)-\mathrm{O}(10)$ & $2.416(5)$ & $\mathrm{Tb}(2)-\mathrm{O}(11)$ & $2.442(5)$ \\
$\mathrm{Tb}(2)-\mathrm{O}(13)$ & $2.453(5)$ & $\mathrm{Tb}(2)-\mathrm{O}(8)$ & $2.460(5)$ \\
$\mathrm{Tb}(2)-\mathrm{O}(9)$ & $2.463(5)$ & $\mathrm{Tb}(2)-\mathrm{O}(4)$ & $2.472(5)$ \\
$\mathrm{Tb}(2)-\mathrm{O}(14)$ & $2.578(5)$ & $\mathrm{Tb}(2)-\mathrm{N}(2)$ & $2.756(6)$ \\
$\mathrm{O}(1)-\mathrm{Tb}(1)-\mathrm{O}(5)$ & $71.08(16)$ & $\mathrm{O}(5)-\mathrm{Tb}(1)-\mathrm{O}(12)$ & $146.94(16)$ \\
$\mathrm{O}(5)-\mathrm{Tb}(1)-\mathrm{O}(2)$ & $70.50(17)$ & $\mathrm{O}(1)-\mathrm{Tb}(1)-\mathrm{O}(7)$ & $75.31(18)$ \\
$\mathrm{O}(3)-\mathrm{Tb}(1)-\mathrm{O}(6)$ & $67.11(16)$ & $\mathrm{O}(2)-\mathrm{Tb}(1)-\mathrm{O}(12)$ & $140.42(16)$ \\
$\mathrm{O}(1)-\mathrm{Tb}(1)-\mathrm{N}(1)$ & $143.80(20)$ & $\mathrm{O}(2)-\mathrm{Tb}(1)-\mathrm{N}(1)$ & $69.66(19)$ \\
$\mathrm{O}(10)-\mathrm{Tb}(2)-\mathrm{O}(14)$ & $68.68(16)$ & $\mathrm{O}(8)-\mathrm{Tb}(2)-\mathrm{O}(14)$ & $73.65(18)$ \\
$\mathrm{O}(10)-\mathrm{Tb}(2)-\mathrm{O}(8)$ & $74.94(19)$ & $\mathrm{O}(13)-\mathrm{Tb}(2)-\mathrm{O}(8)$ & $85.19(18)$ \\
$\mathrm{O}(10)-\mathrm{Tb}(2)-\mathrm{O}(11)$ & $119.95(18)$ & $\mathrm{O}(9)-\mathrm{Tb}(2)-\mathrm{O}(14)$ & $133.66(19)$ \\
$\mathrm{O}(10)-\mathrm{Tb}(2)-\mathrm{N}(2)$ & $143.60(20)$ & $\mathrm{O}(4)-\mathrm{Tb}(2)-\mathrm{N}(2)$ & $69.27(19)$ \\
\hline
\end{tabular}

Mo Ka radiation $(\lambda=0.71073 \AA$ ). Crystal data, data collection parameters, and analysis statistics for compound $\mathbf{1}$ are listed in Table 1. Selected bond lengths and angles are given in Table 2. The frames were integrated in the Siemens SAINTPLUS software package [26], and the data were corrected for absorption using the SADABS program [27]. The structures were solved by the direct method (SHELXS 97) and expanded using Fourier techniques. The nonhydrogen atoms were refined anisotropically. The hydrogen atoms attached to carbon atoms and oxygen atoms were inserted at the calculated positions and allowed to ride on their respective parent atoms. Crystallographic data for the structure reported in this article have been deposited with the Cambridge Crystallographic Data Center as CCDC 1835084.

\section{Results and discussion}

\subsection{General characterization}

In the flourier transform infrared spectrum (FT-IR) of compound 1 (Fig. S1), the absence of the bands around $1666 \mathrm{~cm}^{-1}, 1274 \mathrm{~cm}^{-1}$, and $934 \mathrm{~cm}^{-f}$ (the characteristic bands of $\mathrm{U}_{\mathrm{C}=\mathrm{O}}, \mathrm{U}_{\mathrm{O}-\mathrm{H}}$, and $\delta_{\mathrm{O}-\mathrm{H}}$ of carboxylic acid groups in free ligands, respectively) indicates the complete coordination and deprotonating of the carboxylic group of the ligand $\mathrm{H}_{2} \mathrm{~L}$. On the other hand, the frequency separations $(\Delta v)$ between the asymmetric $\left(v_{\text {as }}\right)$ and symmetric $\left(v_{s}\right)$ stretching modes of the carboxylic units also provide an indication of its bridging coordination mode. For compound $1, v_{\text {as }}\left(\mathrm{COO}^{-}\right)=1553 \mathrm{~cm}^{-1}, v_{\mathrm{s}}\left(\mathrm{COO}^{-}\right)=1384 \mathrm{~cm}^{-1}$, $\Delta v$ is $169 \mathrm{~cm}^{-1}$ which lies in the range of $160170 \mathrm{~cm}^{-1}$ (bridging mode for $\mathrm{COO}^{-}$group) $[28,29] . \Delta v$ for free ligand $\mathbf{H}_{\mathbf{2}} \mathbf{L}$ is $251 \mathrm{~cm}^{-1}$ (Fig. S2). The broad band at ca. $3396 \mathrm{~cm}^{-1}$ is ascribed to the $\mathrm{OH}$ vibration for the coordinating methanol molecule.

\subsection{Preparation of compound 1, $\left[\mathrm{Tb}_{2} \mathrm{~L}_{3}(\mathrm{Py})_{2}\left(\mathrm{CH}_{3} \mathrm{OH}\right)_{2}\right]_{n}$.}

A solution of $\mathrm{Tb}\left(\mathrm{NO}_{3}\right)_{3} \cdot 6 \mathrm{H}_{2} \mathrm{O}(0.0453 \mathrm{~g}, 0.1 \mathrm{mmol})$ in $10 \mathrm{~mL}$ methanol was carefully layered on a solution of $\mathrm{H}_{2} \mathbf{L}(0.017 \mathrm{~g}, 0.1 \mathrm{mmol})$ in a mixed solvent of $10 \mathrm{~mL} \mathrm{H}_{2} \mathrm{O}$ and $1.5 \mathrm{~mL}$ pyridine with $1 \mathrm{~mL} \mathrm{H}_{2} \mathrm{O}$ as a buffer in the middle of two layers in a vial and then sealed. About 2 weeks later, colorless block crystals were found on the wall of vial. Products were carefully picked and washed with methanol three times, and then dried at room temperature. Yield: $63.7 \%$ (based on Tb). Anal. Calcd\% (found\%) for $\mathrm{C}_{30} \mathrm{H}_{24} \mathrm{~N}_{2} \mathrm{O}_{14} \mathrm{~S}_{3} \mathrm{~Tb}_{2}: \mathrm{C}, 34.30$ (34.19); $\mathrm{H}, 2.30$ (2.28); N, 2.67 (2.71). IR $v_{\mathrm{KBr}}\left(\mathrm{cm}^{-1}\right): 3397 \mathrm{br}, 1553 \mathrm{~s}, 1473 \mathrm{w}, 1441 \mathrm{w}$, $1384 \mathrm{~s}, 1215 \mathrm{w}, 1128 \mathrm{w}, 1033 \mathrm{w}, 825 \mathrm{w}, 773 \mathrm{~m}, 703 \mathrm{w}, 684 \mathrm{w}$, $546 \mathrm{w}, 473 \mathrm{w}$.

The experimental powder $\mathrm{X}$-ray diffraction (PXRD) pattern of compound $\mathbf{1}$ agrees mainly with the simulated one from the single-crystal X-ray diffraction data (Fig. S3), indicating that it is in pure phase. The minor difference 
between small peaks should be due to little amorphous component in the crystallized product or the loss of coordinated methanol and pyridine molecules when preparing powder sample for PXRD experiment.

Photos taken by scanning electron microscopy (SEM) showed that MOFs were formed with shapes of prism and other kinds of blocks (Fig. 1). It can be seen from the last three photos that MOF was formed layer by layer with the thickness of about $2 \mu \mathrm{m}$. From the last photo we can see some small amorphous solid covering the layers of MOF with clear edges.

\subsection{Description of crystal structure}

Compound 1 crystallizes in the space group $P$ - 1 . In this structure, there are two independent $\mathrm{Tb}$ (III) metal centers, $\mathrm{Tb}(1)$ and $\mathrm{Tb}(2)$. However, both $\mathrm{Tb}$ (III) metal centers are all coordinated by one pyridine $\mathrm{N}$ atom, one $\mathrm{O}$ atom from one methanol molecule, and six carboxylic $\mathrm{O}$ atoms from six carboxylate groups of six different organic ligands, defining a distorted square antiprism $\left(\mathrm{D}_{4 \mathrm{~d}}\right)$ geometry (Fig. 2$)$. The bond angles around the $\mathrm{Tb}(1)$ and $\mathrm{Tb}(2)$ metal centers range from $67.11(16)^{\circ}$ to $146.94(16)^{\circ}$. The $\mathrm{Tb}-\mathrm{N}$ bond distances relating to two metal centers range from 2.733(6) $\AA$ to $2.756(6) \AA$, the $\mathrm{Tb}-\mathrm{O}_{\text {methanol }}$ bond distances range from $2.578(5) \AA$ to 2.609 (5) $\AA$, and the $\mathrm{Tb}-\mathrm{O}_{\text {carboxylate }}$ bond distances range from $2.416(5) \AA ̊$ to $2.578(5) \AA$ which are in

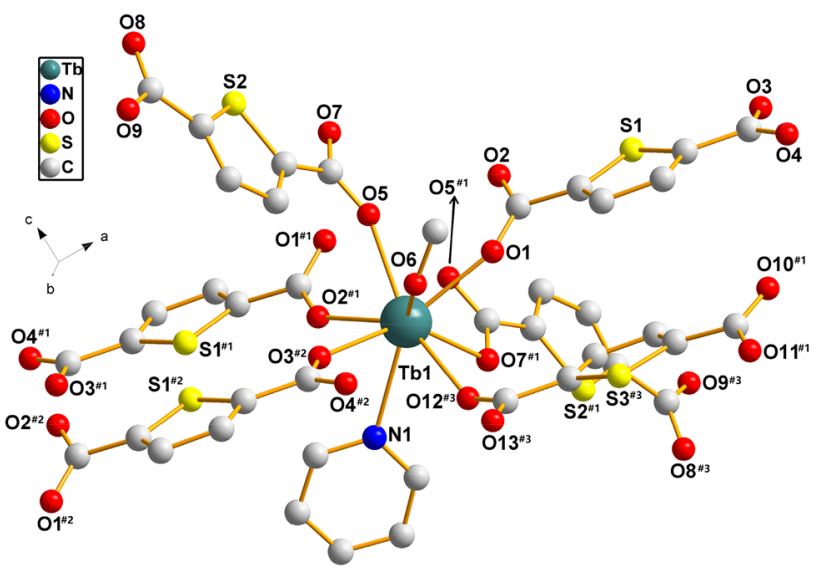

Fig. 2 Ball-stick diagram showing the coordination arrangement around the Tb center (hydrogen atoms omitted for clarity. Symmetric codes: \#1 1-x, 1-y, -z; \#2 -1 + x, y, z; \#3 1+x, y, -1+z)

accordance with those in previously reported $\mathrm{Tb}$ (III) coordination polymers [30-32].

Angular organic ligands $\mathbf{L}$ act as the only bridges that a three-dimensional Terbium-organic framework is constructed. Four $\mathrm{Tb}$ (III) ions are linked by one $\mathbf{L}$ anion as a bridging bidentate ligand through two carboxylic groups in syn-syn and syn-anti configurations in one ligand (Fig. S4). First, two adjacent $\mathrm{Tb}(\mathrm{III})$ ions are linked together by four carboxylic groups in the syn-syn mode and another two neighboring $\mathrm{Tb}(\mathrm{III})$ ions are linked together by two
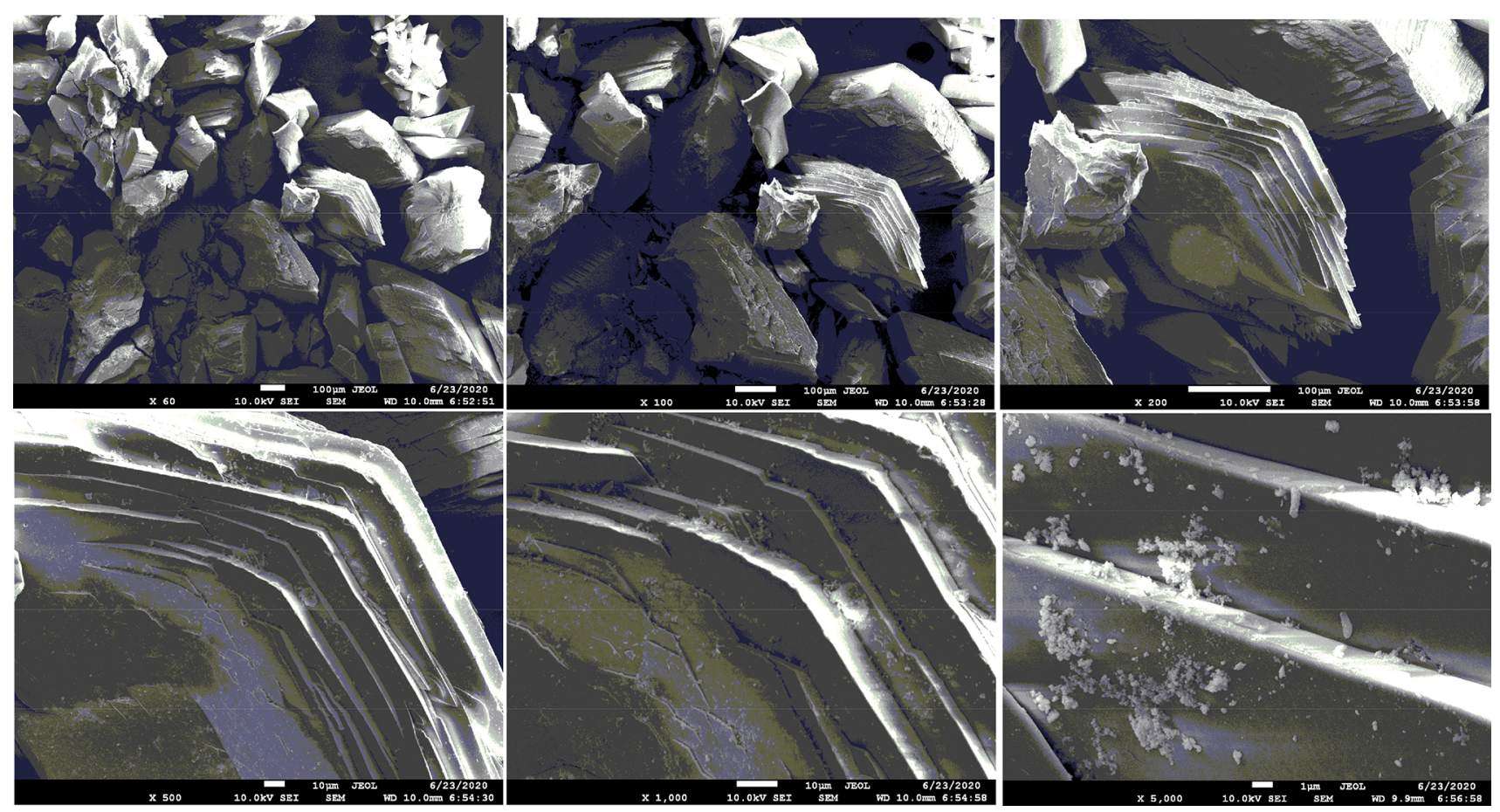

Fig. 1 SEM images of MOFs

\section{SN Applied Sciences}




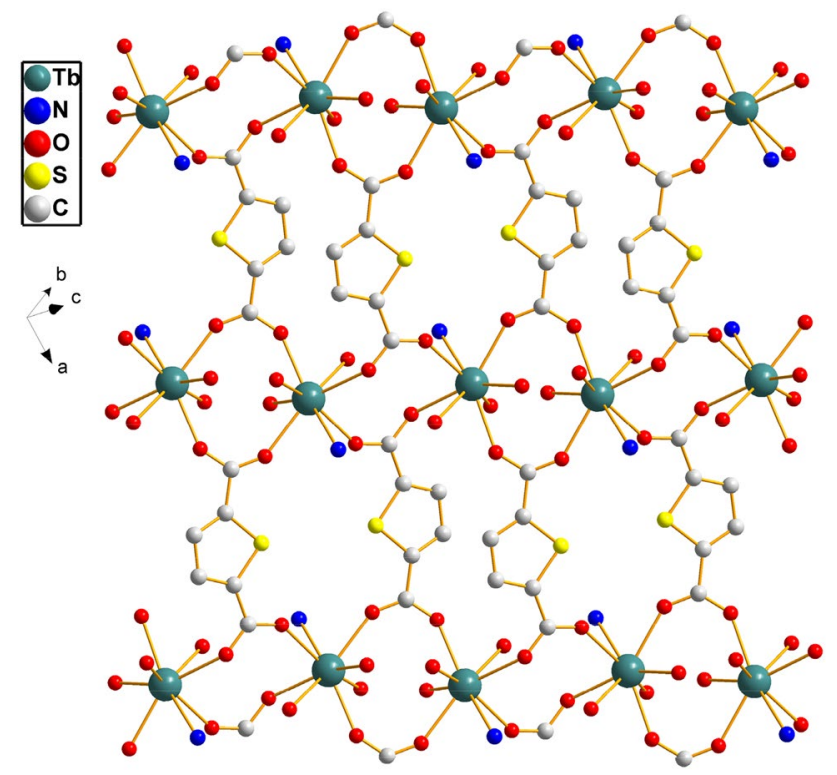

Fig. 3 Ball-stick diagram showing the two-dimensional layer (hydrogen atoms omitted for clarity)

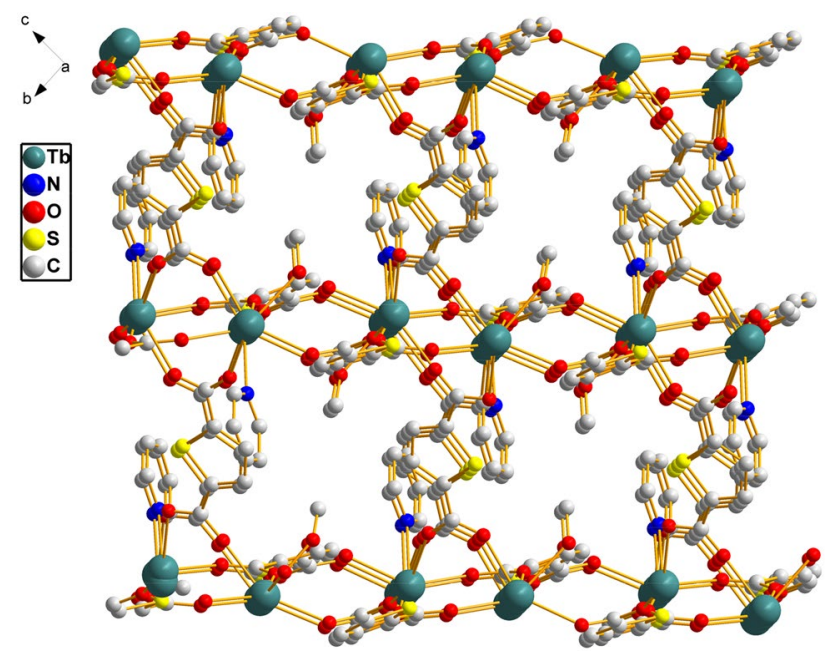

Fig. 4 Ball-stick diagram showing the metal-organic frameworks along $a$ axis (hydrogen atoms omitted for clarity)

carboxylic groups in the syn-anti mode. In this way, one-dimensional metal clusters are constructed. Then, those parallel one-dimensional metal clusters are linked together by parallel organic ligands along one direction to form two-dimensional planes (Fig. 3). Finally, twodimensional layers are also linked together by organic ligands along the perpendicular direction of layers to form the three-dimensional metal-organic frameworks. Along with $a$ axis, there are channels with the dimension of ca. $0.5 \times 0.5 \mathrm{~nm}^{2}$ among the organic ligands and coordinated methanol molecules (Fig. 4). Furthermore, along the direction that is parallel to one-dimensional metal clusters there are possible large-scale channels (ca. $1.6 \times 1.6 \mathrm{~nm}^{2}$ ) occupied by coordinating pyridine molecules which can be removed by heating as illustrated in TGA curve in the next part (Fig. 5). Unfortunately, nitrogen gas adsorption and desorption experiments at $77 \mathrm{~K}$ showed that solid sample after removing methanol and pyridine at $300{ }^{\circ} \mathrm{C}$ did not possess large pores and surface area maybe due to the framework collapse without methanol or pyridine support (Fig. S5).

\subsection{Thermal analysis}

Thermogravimetric analysis (TGA) was performed on a powder sample of compound $\mathbf{1}$ under air circumstances. The thermogravimetric curve of this compound has four steps of obvious weight loss (Fig. 6). The first weight loss of $5.62 \%$ from 30 to $200{ }^{\circ} \mathrm{C}$ corresponds to the loss of two coordinating methanol molecules (calcd 6.10\%). The second step weight loss of $13.88 \%$ from 200 to $350{ }^{\circ} \mathrm{C}$ corresponds to the loss of two coordinating pyridine molecules (calcd $15.06 \%$ ). The third step from 350 to $600{ }^{\circ} \mathrm{C}$ is attributed to decomposition and part loss of the $\mathbf{L}$ organic ligands and the last loss from 600 to $800^{\circ} \mathrm{C}$ is the loss of all component of $\mathbf{L}$ with residue of $\mathrm{Tb}_{2} \mathrm{O}_{3}$. The remaining weight at $35.20 \%$ is likely that of inorganic residue of $\mathrm{Tb}_{2} \mathrm{O}_{3}$ (calcd 34.83\%).

\subsection{Photophysical properties}

UV-Vis adsorption properties were performed to low concentration suspension of compound 1 in DMF $\left(10^{-4} \mathrm{~mol}\right.$ of $\mathbf{L} / \mathrm{L})$ and dilute solution of ligand $\mathrm{H}_{2} \mathbf{L}$ in DMF $\left(10^{-4} \mathrm{~mol} / \mathrm{L}\right)$ at room temperature (Fig. 7). The adsorption peak of compound 1 was significantly higher than that of the organic ligand $\mathrm{H}_{2} \mathrm{~L}$ of the same concentration based on the deprotonated organic ligand $\mathbf{L}^{2-}$. For compound $\mathbf{1}$, the coordination of $\mathrm{Tb}(\mathrm{III})$ to ligand did not change the $\pi-\pi^{*}$ gap but shared the energy absorbed by $\pi$ system in organic ligand and then the whole coordination compound can absorb more energy than organic ligand. Meanwhile, we investigated the fluorescent emission using low concentration suspension of compound $\mathbf{1}$ in DMF with the concentration of $10^{-4} \mathrm{~mol} / \mathrm{L}$. It emitted weak light with the lifetime of $2.36 \mathrm{~ns}$ and small absolute quantum yield of $10.42 \%$ (Fig. S6).

Solid-state fluorescent spectrum determinations were also performed on powder sample of compound $\mathbf{1}$ at room temperature. As shown in Fig. 8, upon the optimized excitation of $325 \mathrm{~nm}$ in the excitation spectrum (Fig. S7), the emission peaks were found at $490 \mathrm{~nm}, 545 \mathrm{~nm}, 586 \mathrm{~nm}$, and $622 \mathrm{~nm}$, which attribute to ${ }^{5} \mathrm{D}_{4} \rightarrow{ }^{7} \mathrm{~F}_{6},{ }^{5} \mathrm{D}_{4} \rightarrow{ }^{7} \mathrm{~F}_{5}$, ${ }^{5} D_{4} \rightarrow{ }^{7} F_{4}$, and ${ }^{5} D_{4} \rightarrow{ }^{7} F_{3}$ transitions, respectively. As indicated in the fluorescent emission graph, the transition of 
Fig. 5 Ball-stick diagram showing the metal-organic frameworks along the onedimensional metal cluster's direction (hydrogen atoms omitted for clarity)
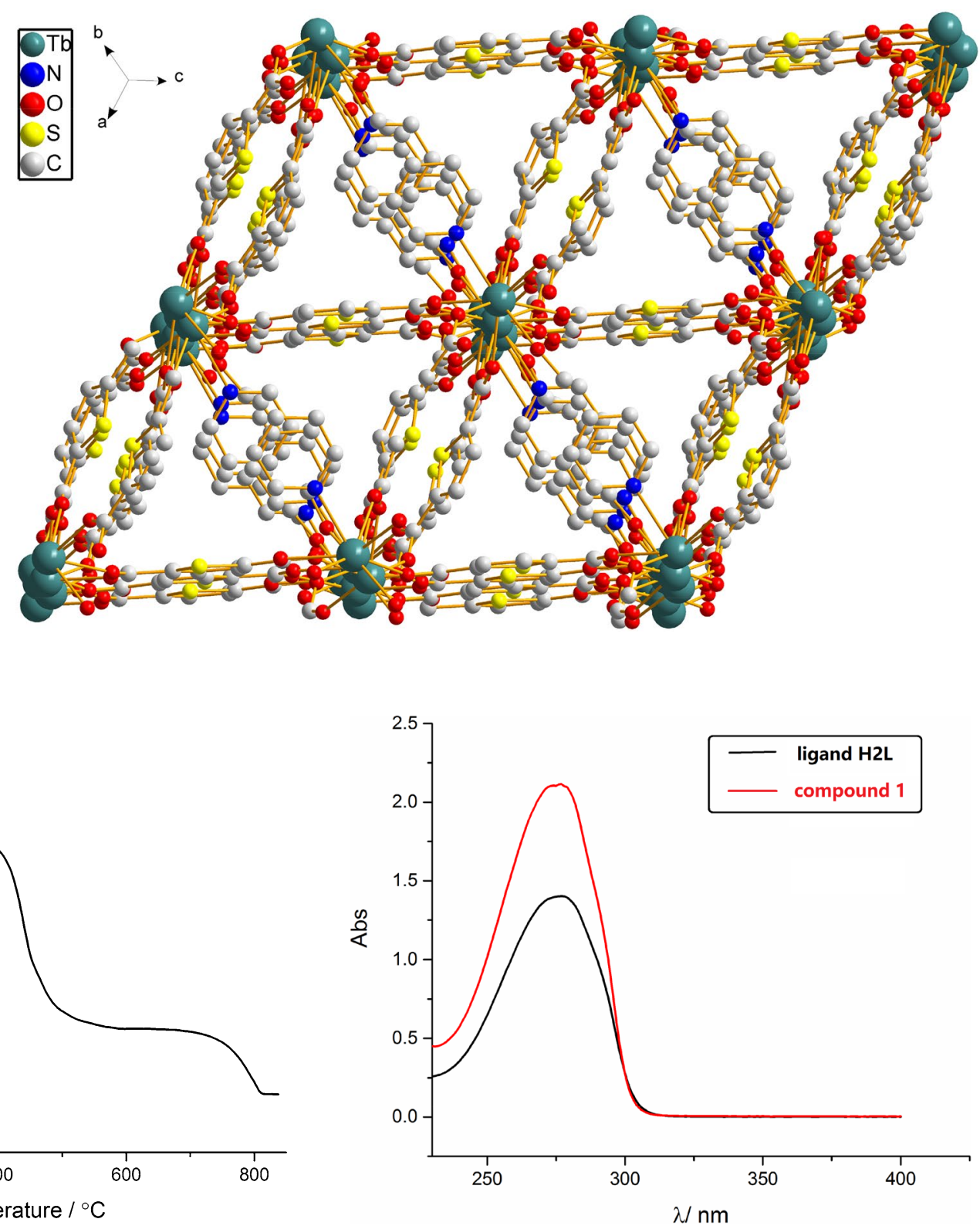

Fig. 6 TGA curve of compound 1

${ }^{5} \mathrm{D}_{4} \rightarrow{ }^{7} \mathrm{~F}_{5}$ shows the strongest emission due to its easiest sensing by organic ligands because the $\mathrm{Tb}$ (III) metal ion is located on the non-centrosymmetric ligand-field position [33]. The lifetime for the solid sample was $2.98 \mathrm{~ns}$ which is a little longer than that for solution (Fig. S8). However, the absolute quantum yield of solid sample was significantly increased to $36.98 \%$ (Fig. S9) that made the powder sample emit very strong green light seen by naked eyes (Fig. 9).

In order to investigate the fluorescent emission of $\mathrm{Tb}$ (III) metal ion sensitized by organic ligand thiophene2,5-dicarboxylate, theoretical calculation by DFT/TD-DFT method using B3LYP/6-31G(d) basis sets was performed to
Fig. 7 UV-Vis absorption spectra of compound $\mathbf{1}$ and $\mathrm{H}_{2} \mathbf{L}$ in DMF $\left(10^{-4} \mathrm{~mol} / \mathrm{L}\right)$ at room temperature (red line: compound $\mathbf{1}$; black line: $\mathrm{H}_{2} \mathbf{L}$ )

assess the molecular orbitals and triplet state of ligand in MOF. As shown in Fig. 10, the electron density of HOMO is mainly located the $\pi$-systems of the thiophene ring while more electron density of LUMO is located at two carboxylic groups. This can explain why this ligand can be used to sensitize the emission of $\mathrm{Tb}(\mathrm{III})$ ion because of more LUMO occupation on carboxylic groups which directly coordinate to $\mathrm{Tb}$ (III) ions and facilitate the energy transfer from organic ligand to $\mathrm{Tb}$ (III) ions. Furthermore, the calculated lowest triplet state energy $\left(T_{1}\right)$ is $22,099 \mathrm{~cm}^{-1}$ which 


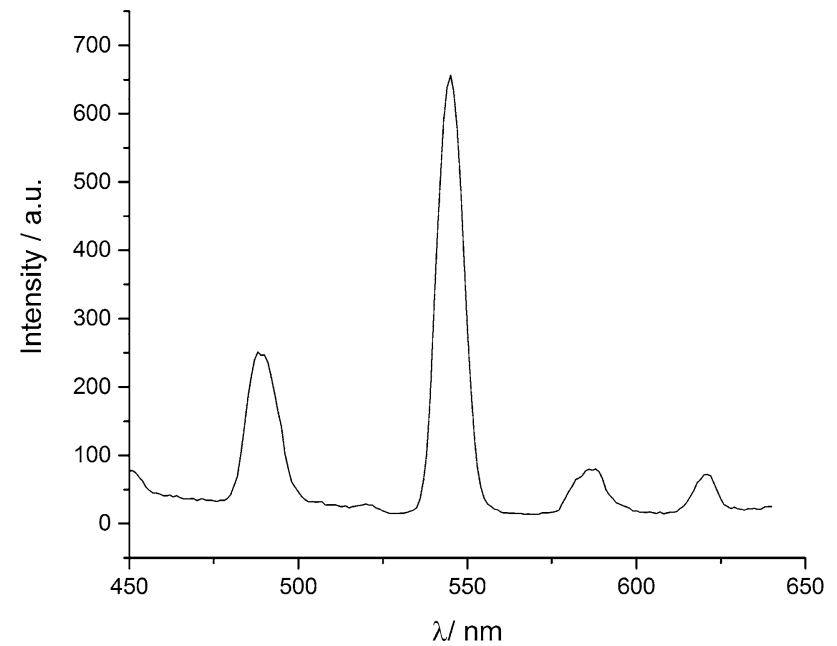

Fig. 8 Emission spectra of compound 1 upon the excitation of $325 \mathrm{~nm}$ in the solid state at room temperature

is $1599 \mathrm{~cm}^{-1}$ (between 1000 and $2000 \mathrm{~cm}^{-1}$ ) higher than the ${ }^{5} \mathrm{D}_{4}$ emitting level $\left(20,500 \mathrm{~cm}^{-1}\right)$ of $\mathrm{Tb}$ (III) ion and sufficiently make the energy transfer process more efficient $[34,31]$.

\section{Conclusion}

In summary, we successfully synthesized a lanthanide metal-organic framework by an angular dicarboxylic acid bridging ligand at room temperature and characterized its fluorescent property. The fluorescent emissions are significant due to the antenna effect of organic ligands that this lanthanide metal-organic compound can be used as lighting materials such as OLEDs.

Acknowledgements We gratefully acknowledge financial support from the Special Scientific Innovation Foundation of Henan Agricultural University (KJCX2015C05) and Top-notch Personnel Fund of Henan Agricultural University (30500418).

\section{Compliance with ethical standards}

Conflict of interest There is no conflict of interest.

\section{Appendix A. Supplementary material}

Figure S1-S9. Crystallographic data (excluding structure factors) reported in this paper have been deposited with the Cambridge Crystallographic Data Center as supplementary publication (CCDC no.: 1835084). Copies of the data can be obtained free of charge on application to
Fig. 9 Photos taken under white light (left) and UV light (365 nm) (right)

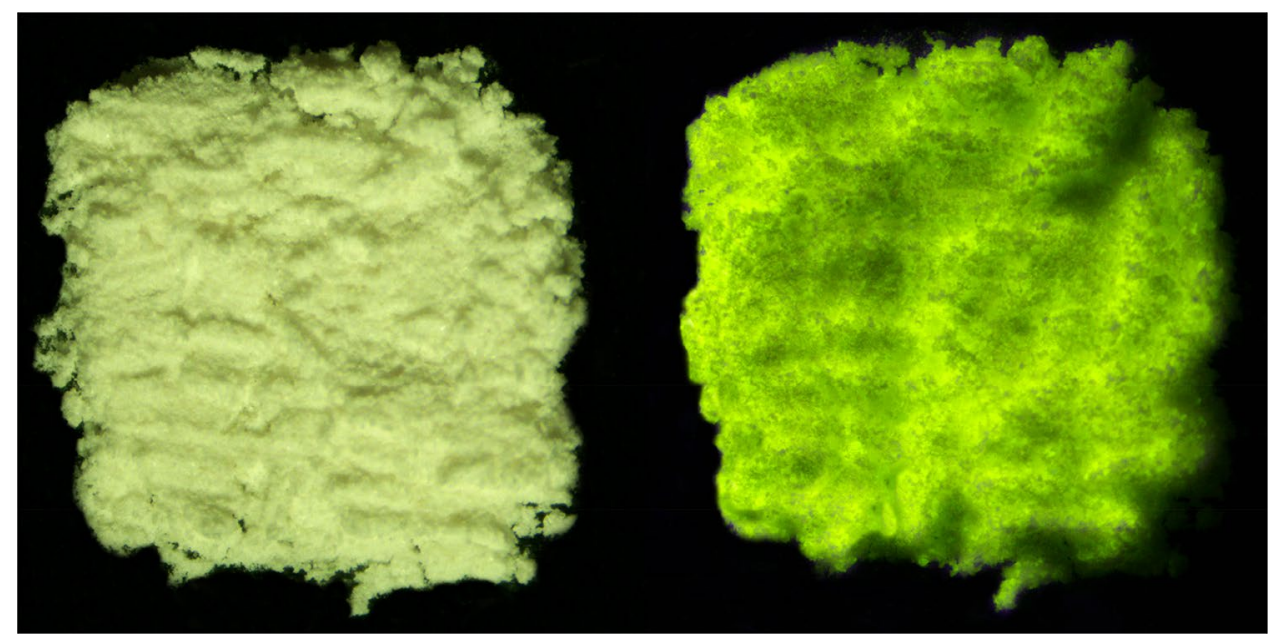

Fig. 10 Calculated $\mathrm{HOMO}$ and LUMO of $\mathrm{H}_{2} \mathrm{~L}$

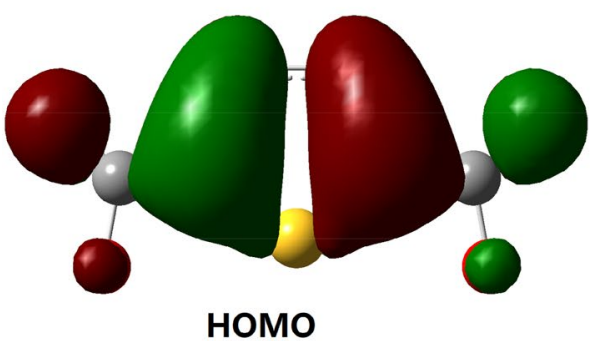

HOMO

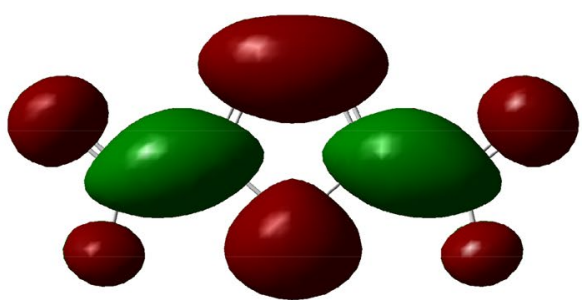

LUMO 
CCDC, 12 Union Road, Cambridge CB21EZ, UK [fax: (+44) 1223-336-033. e-mail: deposit@ccdc.cam.ac.uk].

\section{References}

1. Evans RC, Douglas P, Winscom CJ (2006) Coordination complexes exhibiting room-temperature phosphorescence: evaluation of their suitability as triplet emitters in organic light emitting diodes. Coord Chem Rev 250:2093-2126

2. Ma LN, Liu Y, Li YZ, Hu QX, Hou L, Wang YY (2020) Three lanthanide metal-organic frameworks based on an ether-decorated polycarboxylic acid linker: luminescence $\mathrm{m}, \mathrm{CO}_{2}$ capture and conversion properties. Chem Asian J 15:191-197

3. Coppo P, Duati M, Kozhevnikov VN, Hofstraat JW, Cola LD (2005) White light emission from an assembly comprising luminescent iridium and europium complexes. Angew Chem Int Ed 44:1806-1810

4. Rocha J, Carlos LD, Paz FAA, Ananias D (2011) Luminescent multifunctional lanthanides-based metal-organic frameworks. Chem Soc Rev 40:926-940

5. Wang MX, Long LS, Huang RB, Zheng LS (2011) Influence of halide ions on the chirality and luminescent property of ionothermally synthesized lanthanide-based metal-organic frameworks. Chem Commun 47:9834-9836

6. Luo LL, Qu XL, Li Z, Li X, Sun HL (2018) Isostructural lanthanidebased metal-organic frameworks: structure, photoluminescence and magnetic properties. Dalton Trans 47:925-934

7. Zhang XM, Li P, Gao W, Liu F, Liu JP (2016) Construction of three lanthanide metal-organic frameworks: synthesis, structure, magnetic properties and highly selective sensing of metal ions. J Solid State Chem 244:6-11

8. Liu K, Li H, Zhang X, Shi W, Cheng P (2015) Constraining and tuning the coordination geometry of a lanthanide ion in metalorganic frameworks: approach toward a single-molecule magnet. Inorg Chem 54:10224-10231

9. Jing $T$, Chen $L$, Jiang $F$, Yang $Y$, Zhou K, Yu M, Cao Z, Li S, Hong M (2018) Fabrication of a robust lanthanide metal-organic framework as a multifunctional material for $\mathrm{Fe}$ (III) detection, $\mathrm{CO}_{2}$ capture, and utilization. Cryst Growth Des 18:2956-2963

10. Zhu Y, Wang Y, Liu P, Xia C, Wu Y, Lu X, Xie J (2015) Two chelatingamino-functionalized lanthanide metal-organic frameworks for adsorption and catalysis. Dalton Trans 44:1955-1961

11. Ma J, Guo J, Wang H, Li B, Yang T, Chen B (2017) Microporous lanthanide metal-organic framework constructed from lanthanide metalloligand for selective separation of $\mathrm{C}_{2} \mathrm{H}_{2} / \mathrm{CO}_{2}$ and $\mathrm{C}_{2} \mathrm{H}_{2} /$ $\mathrm{CH}_{4}$ at room temperature. Inorg Chem 56:7145-7150

12. Cui $Y, X u$ H, Yue $Y$, Guo Z, Yu J, Chen Z, Gao J, Yang Y, Qian G, Chen $B$ (2012) A luminescent mixed-lanthanide metal-organic framework thermometer. J Am Chem Soc 134:3979-3982

13. Wang XY, Yao X, Huang Q, Li YX, An GH, Li GM (2018) Triplewavelength-region luminescence sensing based on a colortunable emitting lanthanide metal-organic framework. Anal Chem 90:6675-6682

14. Shi BB, Zhong YH, Guo LL, Li G (2015) Two dimethylphenyl imidazole dicarboxylate-based lanthanide metal-organic frameworks for luminescence sensing of benzaldehyde. Dalton Trans 44:4362-4369

15. Wang HR, Qin JH, Huang C, Han Y, Xu WJ, Hou HW (2016) Mono-/ bimetallic water-stable lanthanide coordination polymers as luminescent probe for detecting cations, anions and organic solvent molecules. Dalton Trans 45:12710-12716
16. Zhao Y, Wang YJ, Wang N, Zheng P, Fu HR, Han ML, Ma LF, Wang LY (2019) Tetraphenylethylene-decorated metal-organic frameworks as energy-transfer platform for the detection of nitro-antibiotics and white-light emission. Inorg Chem 58:12700-12706

17. Zhou Z, Han ML, Fu HR, Ma LF, Luo F, Li DS (2018) Engineering design toward exploring the functional group substitution in 1D channels of $\mathrm{Zn}$-organic frameworks upon nitro explosives and antibiotics detection. Dalton Trans 47:5359-5365

18. Xie XX, Yang YC, Dou BH, Li ZF, Li G (2020) Proton conductive carboxylate-based metal-organic frameworks. Coord Chem Rev 404:213100

19. Carter KP, Zulato CHF, Rodrigues EM, Pope SJA, Sigoli FA, Cahill $C L$ (2015) Controlling dimensionality via a dual ligand strategy in Ln-thiophene-2,5-dicarboxylic acid-terpyridine coordination polymers. Dalton Trans 44:15843-15854

20. Yan B (2017) Lanthanide-functionalized metal-organic framework hybrid systems to create multiple luminescent centers for chemical sensing. Acc Chem Res 50:2789-2798

21. Zhan CH, Wang F, Kang Y, Zhang J (2012) Lanthanide-thiophene2,5-dicarboxylate frameworks: ionothermal synthesis, helical structures, photoluminescent properties, and single-crystalto-single-crystal guest exchange. Inorg Chem 51:523-530

22. Liu JQ, Luo ZD, Pan Y, Singh AK, Trivedi M, Kumar A (2020) Recent developments in luminescent coordination polymers: designing strategies, sensing application and theoretical evidences. Coord Chem Rev 406:213145

23. Fu HR, Zhao Y, Xie T, Han ML, Ma LF, Zang SQ (2018) Stable dyeencapsulated indium-organic framework as dual-emitting sensor for the detection of $\mathrm{Hg}^{2+} / \mathrm{Cr}_{2} \mathrm{O}_{7}{ }^{2-}$ and a wide range of nitro-compounds. J Mater Chem C 6:6440-6448

24. Han ML, Chang XH, Feng X, Ma LF, Wang LY (2014) Temperature and $\mathrm{pH}$ driven self-assembly of $\mathrm{Zn}$ (II) coordination polymers: crystal structures, supramolecular isomerism, and photoluminescence. CrystEngComm 16:1687-1695

25. Niu CY, Zheng XF, Wan XS, Kou CH (2011) A series of two-dimensional $\mathrm{Co}(\mathrm{II}), \mathrm{Mn}(\mathrm{II})$, and $\mathrm{Ni}(\mathrm{II})$ coordination polymers with di- or trinuclear secondary building units constructed by 1,1'-biphenyl-3,3'-dicarboxylic acid: synthesis, structures, and magnetic properties. Cryst Growth Des 11:2874-2888

26. Bruker AXS (1998) SAINT Software reference manual. Madison, WI

27. Sheldrick GM (1997) SHELXTL NT Version 5.1. Program for solution and refinement of crystal structures. University of Göttingen, Germany

28. Nara M, Torii H, Tasumi M (1996) Correlation between the vibrational frequencies of the carboxylate group and the types of its coordination to a metal ion: an ab initio molecular orbital study. J Phys Chem 100:19812-19817

29. Nara M, Morii H, Tanokura M (2013) Coordination to divalent cations by calcium-binding proteins studied by FTIR spectroscopy. Biochim Biophys Acta 1828:2319-2327

30. Bogale RF, Chen Y, Ye J, Zhang S, Li Y, Liu X, Zheng T, Rauf A, Ning $\mathrm{G}$ (2017) A terbium(III)-based coordination polymer for selective and sensitive sensing of nitroaromatics and ferric ion: synthesis, crystal structure and photoluminescence properties. New J Chem 41:12713-12720

31. Gai Y, Jiang F, Chen L, Wu M, Su K, Pan J, Wan X, Hong M (2014) Europium and terbium coordination polymers assembled from hexacarboxylate ligands: structures and luminescent properties. Cryst Growth Des 14:1010-1017

32. Liu GF, Qiao ZP, Wang HZ, Chen XM, Yang G (2002) Synthesis, structures and photoluminescence of three terbium(III) dicarboxylate coordination polymers. New J Chem 26:791-795 
33. Bünzli JCG (2015) On the design of highly luminescent lanthanide complexes. Coord Chem Rev 293-194:19-47

34. Bulach V, Sguerra F, Hosseini MW (2012) Porphyrin lanthanide complexes for NIR emssion. Coord Chem Rev 256:1468-1478
Publisher's Note Springer Nature remains neutral with regard to jurisdictional claims in published maps and institutional affiliations. 